\title{
Evolving China in the Global Climate Norm-Making: Development Models, National Roles and International Contexts
}

\author{
Meijie JIANG*
}

\begin{abstract}
As the world's second largest economy and largest emitter of greenhouse gases, China's participation in global climate governance has gained worldwide attention and has been under closer international scrutiny. This paper aims to understand China's motivations and underlying forces that have driven its positions, practices and choices in this regard, particularly when negotiating and complying with the UNFCCC, Kyoto Protocol and Paris Agreement. For this end, the article focuses on the changes and continuities of China in the evolving international climate norm-making. I argue that China's roles and engagement in the processes have been fundamentally shaped by development patterns, perception of national roles, and international contexts. The paper concludes that based on social, political and economic conditions, a mutual understanding and learning between China and other countries can reveal insights on global governance in the future.
\end{abstract}

Keywords: China - global climate governance - norm-making - UNFCCC - Kyoto Protocol - Paris Agreement development - national role - international politics

\section{(A) INTRODUCTION}

In the aftermath of World War II, non-traditional security threats have increased substantially. International norms and global governance have emerged and have become more salient in the wake of globalization as a result of interdependence. These areas cannot be solved by any single government and are often regulated involving international treaties and conventions with the support of states, international organizations, and private sectors when necessary. ${ }^{1}$ Within global commons, climate and environment concern is a matter of special urgency. Dramatic atmosphere changes and accompanying extreme weather conditions, which bring about hurricanes, floods and droughts, are now affecting agricultural and livestock development in all countries and directly threatening food security and human's survival. ${ }^{2}$ Furthermore, global warming and environment problems have evolved from a country-specific matter to a global issue that affects various fields such as politics, economy, energy, ecology, and health, becoming one of the most pressing issues worldwide.

Global efforts to address climate issues are normalized from the United Nations Conference on Human Environment in 1972. Then, several rounds of international negotiations established a series of environmental decisions. In 1992, leaders of over 170 countries attended the United Nations Conference on Environment and Development to discuss global sustainable development. ${ }^{3}$ The

* PhD candidate at Pompeu Fabra University. Email: meijie.jiang@upf.edu.

1 M. Burnay \& J. Chaisse, 'Global Commons as an Emerging Arena of Contestation of Global Governance Structures and Norms', 22 International Community Law Review (2020) 533-558, at 535 [doi: 10.1163/1871973212341446].

2 A. Savaresi, 'The Paris Agreement: A New Beginning?', 34 Journal of Energy \& Natural Resources Law (2016) 16-26, [doi: 10.1080/02646811.2016.1133983].

3 J. Guo, 'On China's Energy Saving and Emission Reduction and International Law Analysis about Global Climate Change', 5 Energy Procedia (2011) 2568-2575, [doi: 10.1016/j.egypro.2011.03.441]. 
Conference issued one of the first and most important environment-related documents, United Nations Framework Convention on Climate Change (UNFCCC), which laid down the foundation of the international legal regime for mitigating climate change.

In order to achieve the UNFCCC objectives, the Kyoto Protocol, which includes legally binding targets for developed countries to reduce greenhouse gas (GHG) emissions, was introduced at the third Conference of the Parties (COP) of the UNFCCC in Kyoto. ${ }^{4}$ However, global climate governance stagnated, even though it established a "top-down" governance model. Since the Kyoto Protocol imposes binding emissions reduction commitments on developed countries, it has raised concerns about fair and equal allocation of mitigation burden and quantitative tasks as well as the potential adverse effects of such measures on their economies. ${ }^{5}$ How to understand the principle of "common but differentiated responsibility" remains deeply contested. The international community began to actively explore institutional models that are more suitable for the unique attributes of climate governance. From the beginning of the Bali Roadmap to the initial formation of the Copenhagen Conference and the formal establishment of the Paris Agreement, a bottom-up autonomous contribution model replaced the Kyoto mechanism as the dominant governance model. ${ }^{6}$ This model allows governments to set their own goals or ambitions in mitigation efforts, and to avoid distributional conflicts in subsequent negotiations, which are the major obstacles to cooperation. ${ }^{7}$ The agreement adopted a system of nationally determined contributions (NDCs), which need to be communicated every five years and must include mitigation measures and represent a progress over the country's previous NDCs. It also encourages developing countries to establish increasingly ambitious mitigation targets by supporting their adaptation efforts via technology transfer and finance aid. ${ }^{8}$

Traditionally, normative development on climate change has been largely viewed as the domain of the West, with Europe and the United States (U.S.) as agenda setters over decades. However, Trump announced withdrawal from the Paris Agreement shortly after taking office. Clearly, the withdrawal undermines the universality of the Paris Agreement, which is primarily distinguished from the Kyoto Protocol by the joint participation of both industrialized and developing countries. ${ }^{9}$ Moreover, the British decision to leave the European Union (EU) on the 29th of March of 2019 caused an internal rift within the EU, which has traditionally been at the forefront of global climate governance. This, combined with the EU's slow economic growth in recent years and the impact of the refugee crisis, has significantly reduced the EU's leadership in global climate governance. ${ }^{10}$ Thus, the United States' withdrawal from the climate agreement and the relative decline of the EU's influence have created a leadership deficit in global climate governance.

\footnotetext{
4 H. Jiang, 'Environmental Reviews and Case Studies: The Laws of Climate Change in China', 16 Environmental Practice (2014) 205-229, [doi: 10.1017/S1466046614000155].

5 J. Brunnée \& Ch. Streck, 'The UNFCCC as a Negotiation Forum: Towards Common but More Differentiated Responsibilities', 13 Climate Policy (2013) 589-607, at 601 [doi: 10.1080/14693062.2013.822661].

6 Savaresi, supra n. 2; H. Zhang et al., 'U.S. Withdrawal from the Paris Agreement: Reasons, Impacts, and China's Response', 8 Advances in Climate Change Research (2017) 220-225, [doi: 10.1016/J.ACCRE.2017.09.002].

7 R.S. Dimitrov, 'The Paris Agreement on Climate Change: Behind Closed Doors', 16 Global Environmental Politics (2016) 1-11, [doi: 10.1162/GLEP_a_00361].

8 M. Luomi, 'Is the Paris Agreement a Success and What Does It Mean for the Energy Sector?' Oxford Energy Forum (2016).

9 Zhang et al., supra n. 6.

10 Ibid., at 224.
} 
After becoming the world's second largest economy and largest emitter of greenhouse gases, China's participation in global climate governance has gained worldwide attention and been under closer international scrutiny. China's positions, practices, and choices in this regard have evolved over time as a result of the country's varying development stages and global circumstances. ${ }^{11}$ Therefore, it is particularly necessary to understand China's motivations and underlying forces that have driven changes and continuities in global climate norms. Since the UNFCCC, Kyoto Protocol and Paris Agreement have cemented the legal and normative foundation of global climate governance, this paper tries to shed more light on the roles that China plays when negotiating and ratifying different agreements and how China has evolved in shaping global environmental norms.

\section{(B) ANALYTICAL FRAMEWORK}

As we explore the motivation and strategic considerations of China's engagement with climate issues at different times, I adopt an analytical framework of three dimensions: economic development models, national roles, and international politics. With a framework that combines legal and political perspectives, domestic and international factors, constructivism and realism, it is useful to gain a better understanding of China's behaviors in international norm-setting processes.

The three dimensions are not exclusive of each other but overlap in many respects, and their relative levels of importance in China's global climate governance have changed over time. First of all, many authors agree that a state's socioeconomic transitions shape a country's objectives, behaviors and consequences in addressing environmental concerns. S. G. Breslin stated in the last century that the environmental agenda was highly linked with non-environmental issues and the former would remain subordinate to other concerns until some fundamental issues were resolved. ${ }^{12}$ Stephen Tsang and Ans Kolk echoed this observation, finding that in spite of recognizing environmental impact on people's lives, rapid economic development seems to attach more importance than environmental protection measures. ${ }^{13}$ Fabiana Barbi et al. found that in an early stage when GDP growth commanded and mitigation might undermine urbanization, Chinese officials consistently refused to accept any reduction targets before industrialized countries took action first. ${ }^{14}$ As climate change has transcended environmental issues and become more associated with other social and economic benefits, mitigation can be integrated within development interests. Teng Fei and Wang Pu focus on the state's quest for performance legitimacy. They point out economic growth alone is not sufficient to respond to governing pressures and the government must pursue a broader range of socially beneficial public goods. ${ }^{15}$

Second, states' cognition on national roles and identity determines their participation in global governance. Similar perceptions of identity bring actors closer together, and they are more able to reach consensus and form alliances in the process of negotiations. On the contrary, different identities

11 F. Teng \& P. Wang, 'The Evolution of Climate Governance in China: Drivers, Features, and Effectiveness', Environmental Politics (2021) 1-21, [doi: 10.1080/09644016.2021.1985221].

12 S.G. Breslin, 'Sustainable Development in China', 4 Sustainable Development (1996) 103-108, at 107 [doi: 10.1002/(SICI)1099-1719(199608)4:2\%3C103::AID-SD38\%3E3.0.CO;2-K].

13 S. Tsang \& A. Kolk, 'The Evolution of Chinese Policies and Governance Structures on Environment, Energy and Climate', 20 Environmental Policy and Governance (2010) 180-196, [doi: 10.1002/EET.540].

14 F. Barbi et al., 'Climate Change Challenges and China's Response: Mitigation and Governance', 1 Journal of Chinese Governance (2016) 324-339, [doi: 10.1080/23812346.2016.1181598].

15 F. Teng \& P. Wang, supra n. 11. 
may result in more divisions or even conflicts, which will ultimately result in global governance failure. Under the coalition of Group 77 (G77) plus China, the global South managed to leverage their collective influence to embed the principle of common but differentiated responsibility in the conceptual framework of international environmental law. ${ }^{16}$ However, it is not an easy task to maintain a meaningful negotiating position that captures the interests of all developing countries in view of a wide range of socio-economic and political factors that define the national circumstances of each country. Small island states are especially vulnerable to climate change and call for fair allocation of mitigation burden and provisions of financial and technical assistance to countries with capacity limitation.

Third, as part of global governance, the international system sets standards and norms for participation. It provides, in different periods, various platforms through which actors can participate. Global governance unfolds in a way that actors adjust levels of participation and engagement, clarifying their positions. This in turn makes it easier for actors to redefine their roles. As China's stature grows in the world, so does its ambitions with respect to global governance. The largest emerging power expands international reach and global activism and becomes one of the major players in most international domains. ${ }^{17}$ Chinese President Xi Jinping initiated and reiterates in various occasions the concept of "community with a shared future of mankind" which implies that states should consider the legitimacy concerns of others and pursue shared development of all countries, a new philosophy for China's international relation policies. ${ }^{18}$

\section{(C) CHINA'S EVOLVING ENGAGEMENT AND ROLES IN DIFFERENT STAGES}

\section{(1)China's Early Responses}

When the Reform and Opening-up was announced, Chinese decision-makers incorporated the concern about the environment into the Chinese Constitution in 1978, which accelerated the development of nation-wide environmental protection efforts. ${ }^{19}$ One year later, the first Environmental Protection Law started trial implementation. In 1996, China released the first independent plan for environmental protection specifying quantitative objectives.

However, China before 2000 was still an underdeveloped agrarian country lacking capital and technology. A dramatic contrast between prosperous Japan, four "Asian Dragons", and China's backwardness played a crucial role in the perception of national interest of fast-paced economic growth. The government had to mobilize limited resources to develop the economy and eradicate poverty. This has been the overriding priority in political agenda for decades. As the President $\mathrm{Hu}$ Jintao stated at the United Nations climate change summit in 2009, "climate change is an environmental issue, but also, and more importantly, a development issue. [...] Without common development, particularly the development of developing countries, there cannot be a broad and solid basis in the long run for tackling climate change." ${ }^{20}$ The statement implies that economic

16 J. Brunnée \& Ch. Streck, supra n. 5.

17 M. Burnay \& J. Chaisse, supra n. 1.

18 F. Teng \& P. Wang, supra n. 11.

19 Constitution of the People's Republic of China was adopted on March 5, 1978, the first session of the $5^{\text {th }}$ National People's Congress.

20 J. Hu, 'Chinese President Hu Jintao's Speech at the UN Climate Change Summit', Xinhua, September 22, 2009. 
consequences of climate commitments have been crucial considerations for Chinese policymaking. ${ }^{21}$ Furthermore, the low oil prices in the early stage of Reform and Opening-up allowed the country to take full advantage of energy to feed its development. As long as the Chinese and world economy depends heavily on fossil fuels, GHG reduction, which has the potential to hinder economic development, is bound to give way to GDP growth.

Additionally, the administration and institutional structure before 2000 suggests Chinese society viewed climate change primarily in scientific and environmental terms, rather than economic terms. The coordination of China's climate policy began in 1990 with the establishment of the National Leading Group for Climate Change Coordination, which was initially led by the National Meteorological Administration (NMA). The NMA played a key role in conducting early-stage research, participating in international scientific programs, and implementing commitments under the Framework Convention after its ratification in 1992. As climate change became an important issue on international political agenda, China set up an interdepartmental committee to define the governmental positions in future negotiations.

At the same time, China needed to improve the international environment and actively integrate itself into the international community. Since the 1980s, China has moved away from the revolutionary overtones of the past, fully considering national interests and global trends, opting for peaceful development and opening-up to the outside world, with the ultimate goal of achieving national development. In this light, participation in climate negotiations and global climate governance is undoubtedly an effective way to promote China's exchanges with other countries and enhance China's positive image. The United Nations Conference on Human Environment held in Stockholm in 1972 was the first multilateral conference that China attended after returning to the United Nations, marking an important moment for Chinese diplomacy. ${ }^{22}$ Subsequently, China joined a series of agreements on environmental protection. ${ }^{23}$ Certainly, this helps China to integrate into the new international system and also to deepen awareness of global environmental concerns. However, China had little influence in the roadmaps for negotiations and norm-making processes. ${ }^{24}$ The early engagement falls more within the framework of reform, opening-up and economic development.

\section{(2) Transitional Stage During China's Rise}

From the UNFCCC to the entry into force of the Kyoto Protocol, global climate governance shifted from a stage of consultation to one of responsibility sharing. Legally binding international agreements, marked by the formulation and adoption of the Kyoto Protocol, began to enter the global climate governance mechanism. ${ }^{25}$ In parallel, China's socio-economic conditions have evolved as well. The development in the late 1990s basically freed China from material shortage, and China began to pay more attention to the quality of economic development in addition to growth rate. Since the Kyoto Protocol established the basic principles and provided an effective framework and rules for international cooperation to address climate change, China's ratification in 2002 demonstrated a

\footnotetext{
21 S. Tsang \& A. Kolk, supra n. 13, at 191.

22 Ibid., at 185.

23 B. Li, 'A Study of China's Role in Global Climate Governance', Doctoral thesis at Shangdong University (2020) $1-253$, at 112 .

24 Ibid., at 84.

25 J. Kuyper et al., 'Annual Review of Environment and Resources: The Evolution of the UNFCCC', (2018) [doi: 10.1146/annurev-environ].
} 
positive stance regarding international climate cooperation along with its commitment to sustainable development. ${ }^{26}$ In this context, Chinese domestic institutional structure has gone through significant changes. The State Council approved the set-up in 2003 of the National Coordination Committee on Climate Change, including 13 vice ministers from various departments concerned. ${ }^{27}$ It finally became part of National Development and Reform Commission (NDRC), a comprehensive department at the State Council in charge of releasing economic and social policies, making five-year planning, regulating energy prices and other activities. The institutional reform demonstrates that climate change in China is no longer merely a scientific and meteorological issue, but also a political and economic concern connected with state comprehensive development.

After joining the World Trade Organization (WTO), China has become a world factory for manufacturing goods, which brought about large GHG emissions. Numerous quantitative analyses have found carbon emissions embodied in foreign exports account for a significant portion of China's domestic emissions. ${ }^{28}$ That is to say, the rest of the world has avoided significant emissions as a consequence of importing from China, rather than producing domestically. This partly explains the Chinese early stance of rejecting caps on emissions. What accompanies the high-speed economic growth is the hunger for energy, which cannot be met from its own domestic power generation. ${ }^{29}$ After becoming a net importer of oil since 1993, China's dependency on and vulnerability to foreign oil has increased as the international oil market remains uncertain and the political turmoil in oilproducing countries is widespread. In the wake of China's accession to the WTO, the domestic energy market has also come under increasing pressure from international competition, due to outdated oil production equipment and poor management and policies.

Undoubtedly, double-digit growth greatly enhanced living standards in China and transformed China from a poor agricultural country to a semi-industrialized one. Nevertheless, growth based on export and heavy use of fossil fuels caused serious environmental consequences, such as pollution, extreme weather, floods, drought, etc. The government had to shift "from an economic focus to a broader range of socially beneficial public goods" 30 to respond to people's demand for life with quality after meeting their basic needs. The president Hu Jintao developed concepts of "Scientific Outlook of Development" and "Harmonious Society", which are featured by environmentally sustainable and socially inclusive development.

As a result of globalization and interdependence, China has become more engaged with the world. The economic growth and increasing national power have driven China to consider further expanding international influence, which continues to reinforce China's perception of being a responsible emerging country. As the largest developing country, the most populous state, and a permanent member of the United Nations, the international community has demanded China to assume greater responsibilities. The U.S., as the world largest greenhouse gas emitter at that moment, withdrew from the Kyoto Protocol at the beginning of George W. Bush's administration. The American performance left room for China to take a more active part in climate governance. Within the framework of UNFCCC and Kyoto Protocol, China helped African and small island countries improve their capacity to address climate change through bilateral and multilateral channels, compensating for the

\footnotetext{
26 B. Li, supra n. 23, at 117.

27 S. Tsang \& A. Kolk, supra n. 13, at 190.

28 Ibid., at 191.

29 Ibid., at 187.

30 F. Teng \& P. Wang, supra n. 11, at 10.
} 
lost leadership by the United States. ${ }^{31}$ On the other side of the Atlantic, the EU has been a model for global climate governance and has emphasized the importance of regional and international cooperation. Although the withdrawal of the US and Canada caused tremendous concern to the future of the Kyoto Protocol, the EU actively communicated with other states to dismiss doubts and uncertainties to this treaty, encouraging other countries to join or not to leave. ${ }^{32}$ Especially, collaboration with developing countries can provide instrumental support for the EU to maintain green leadership. At the $20^{\text {th }}$ anniversary of the establishment of diplomatic relations between EU and China, the two sides reached a partnership on jointly tackling climate change in 2005 . The year 2010 witnessed the official set-up of the China-EU ministerial dialogue mechanism on climate change. The intergovernmental cooperation reflects the strong will from both sides to strengthen communication and facilitate extensive view-exchanging.

\section{(3)Proactive Engagement under Xi's Presidency}

Starting from the second decade of the $21^{\text {st }}$ century, China began to slow down economic growth. During this period, China has found emissions mitigation to be aligned with national interests in economic rebalancing and environmental improvement. ${ }^{33}$ Viewed as both international responsibility and inherent national interest, climate governance will allow China to optimize and upgrade its economic structure. The $12^{\text {th }}$ and $13^{\text {th }}$ five-year plans included climate change targets as legally binding targets. A series of emission trading systems and low-carbon city pilots were initiated. And sustainability became important criteria for evaluating the performances of local officials. ${ }^{34}$ In the $19^{\text {th }}$ Parties' Congress in 2017, the concept of "Ecological Civilization" has been formally acknowledged as foundations of China's long-term development philosophy. Additionally, Chinese president Xi Jinping emphasized that China should take a "driving seat in international cooperation to respond to climate change" and become "an important participant, contributor, and torchbearer in the global endeavor for ecological civilization". ${ }^{35}$

Regarding global climate norm-making, the Paris Agreement paves the way for a new era in international climate governance, as the successor to the Convention and the Protocol. Compared to previous legal agreements, the Paris Agreement has long-term goals, flexible principles, and operational measures to reduce emissions. The bottom-up approach reduces conflicts between developed and developing countries, encouraging them to comply with emissions reduction targets as a result of the voluntary principle. China has played a significant role in Paris negotiations and the conclusion of the deal. In 2014 and 2015, China and the United States released two joint announcements in this regard, generating substantial impetus to the Paris Conference. ${ }^{36}$ The French climate negotiator Laurence Tubiana applauded the announcement as "very positive", "very important" and "simply remarkable" as the two largest emitters committing to cut off their

\footnotetext{
${ }^{31}$ B. Li, supra n. 23, at 138.

${ }^{32}$ M. Zhang \& J. Gong, 'The Evolvement of China-EU Cooperation on Climate Change and Its New Opportunities under the European Green Deal', Política de La Competencia y Regulación (2020) 1-34, at 13.

${ }^{33}$ F. Teng \& P. Wang, supra n. 11, at 10.

${ }^{34}$ Ibid., p. 11.

35 J. Xi, "Secure a Decisive Victory in Building a Moderately Prosperous Society in All Respects and Strive for the Great Success of Socialism with Chinese Characteristics for a New Era", 2017, at 4.

36 X. Gao, 'The Paris Agreement and Global Climate Governance: China's Role and Contribution',2 China Quarterly of International Strategic Studies (2016) 365-381, at 378 [doi: 10.1142/S2377740016500226].
} 
emissions. ${ }^{37}$ To move the post-2020 climate negotiation forward, China no longer contended over differentiated responsibility, but placed more emphasis on common commitments, calling on each party to take action in the future climate regime. Chinese deep engagement and leading role in climate conferences has helped create opportunities for consensus building between the global North and the global South. ${ }^{38}$

Undoubtedly, the Paris era is not a period without difficulties. In 2016, the United Kingdom held a referendum to leave the EU, and finally confirmed its withdrawal two years later. Consequently, the EU, originally in a joint position of global climate governance leader, found it difficult to make further progress mired in "Brexit", economic recession, refugee concern, populism, etc. ${ }^{39}$ Meanwhile, Trump announced the withdrawal from the Paris agreement on the grounds that it would destroy the US economy and "put the US at a permanent disadvantage", which cast a shadow over post-Paris governance. The unprecedented Covid-19 pandemic hampered the collective progress of the international community to address climate issues. It is in this context that Xi Jinping announced an ambitious target in September 2020 to reach carbon peak before 2030 and achieve carbon neutrality by 2060 . As outlined in the $14^{\text {th }}$ five-year plan (2021-2025), China will set up a double control system of total energy consumption and intensity of fossil energy consumption. As well, the plan promised to promote "clean, low-carbon, safe and efficient use of energy", "transformation of industries, construction, transportation, and other sectors towards low-carbon development". ${ }^{40}$ Without doubt, the ambitious endeavor will encounter difficulties and challenges. China still remains reliant on highcarbon fossil energy, with low energy utilization efficiency. The transition period from carbon peak to carbon neutrality allowed for the country is shorter than that of developed countries. ${ }^{41}$

\section{(D) CONCLUSION}

Climate change has been probably by far the most widely discussed issue, garnering the most attention and resources globally. Throughout the world, it has gradually influenced the political, economic, cultural, scientific, and technological fields in all countries. It is a collective effort of mankind that countries around the globe find countermeasures to reduce emissions, yet their interests are divided due to different economic development, scientific and technological advantages, and greenhouse gas emissions.

Parallel with the evolution of global climate norm-making, China's role and participation in the processes have also changed significantly. During the 1980s and 1990s, China viewed itself as an underdeveloped country, aiming at industrialization, modernization and bringing an end to poverty. Chinese interests in the global climate were confined to scientific research and integration to the international community. Since the beginning of the $21^{\text {st }}$ century, China has gradually incorporated climate issues into its national economic development strategy, shifting from growth with quantity to growth with quality. As the largest developing country, China has developed its identity as a

37 A. Robert, 'Laurence Tubiana: EU-China Climate Agreement Is Conceivable', EURACTIV, January 28, 2015.

38 X. Gao, supra n. 36, at 379.

39 H. Yu, 'Rebalancing Global Climate Governance and China's Endeavor', 5 China Quarterly of International Strategic Studies (2019) 417-435, at 419 [doi: 10.1142/S2377740019500246].

40 Outline of the 14th Five-Year Plan (2021-2025) for National Economic and Social Development and Vision 2035 of the People's Republic of China, 2021.

41 X. Zhao et al., 'Challenges toward Carbon Neutrality in China: Strategies and Countermeasures' 176 Resources, Conservation and Recycling (2022) [doi: 10.1016/j.resconrec.2021.105959]. 
"responsible power" and has begun to enhance environmental management, improve ecological conditions, and scientifically assess the impact of China's environmental problems. The withdrawal of the United States from the Kyoto Protocol and the loss of leading role have left more room for China to fill the void. During Xi's presidency, China has proposed the "Community of Human Destiny" as the "Chinese way" to offer a solution to global climate governance. Meanwhile, China steers gradually away from its reliance on large-scale resource consumption, increasing investment in science, technology and new energy sources. Furthermore, it promised in 2020 to reach carbon peak by 2030 and carbon neutrality by 2060 .

This paper provides a testing ground for observing China's engagement in international normmaking processes, traditionally dominated by the West. Whether being a norm-taker, normchallenger, or norm-shaper, China's participation is fundamentally shaped by development patterns, perceptions of national roles, as well as international contexts. The "Chinese model", "Chinese way" or "Chinese approach" might be difficult to follow for other countries, which generally do not have a centralized governmental system covering such a huge population and land area. Even so, mutual understanding and learning can shed more light on global governance in future, grounded in national social, political and economic contexts. ${ }^{42}$

${ }^{42}$ F. Teng \& P. Wang, supra n. 11, at 18. 